\title{
Interactive comment on "Dynamics of the Askja caldera July 2014 landslide, Iceland, from seismic signal analysis: precursor, motion and aftermath" by Anne Schöpa et al.
}

\section{Anonymous Referee \#2}

Received and published: 9 January 2018

Dynamics of the Askja caldera July 2014 landslide, Iceland, from seismic signal analysis: precursor, motion and aftermath

This paper shows the precursory seismic signal of the Askja caldera landslide. It is well-written, and shows an interesting observation. Authors found that there were upgliding and down-gliding signals in the seismic data before the landslide, and explained they were accelerating and decelerating stick-slip motion preceding the landslide. They reproduced this phenomenon by numerical modeling. The interpretations are interesting, but they are based on relatively strong assumptions. It is fine to use assumptions and make an interpretation, but in the discussion, the assumptions were treated almost 
an accomplished fact. The proposition of landslide early warning is too optimistic after finding only one example of post-report. Please explain the mechanism more carefully or tone down the succeeding discussion.

[Major comments]

One of the assumptions I was not very convinced was that they treated the tremor as continuous stick-slip events with little intervals. It may be true, but the mechanisms of tremors are still debating and there are many other interpretations. Another brave assumption was that the frequency change was caused by the change of loading velocity. It was not easy for me to imagine the acceleration and deceleration of the velocity occur simultaneously at a single body (which is the assumption when you performed long-period inversion).

Many sentences in the discussion (section 6) were an interpretation based on the assumption, but they are discussed without considering assumptions (e.g. page 13 line 23-24, 26-28, page 14 line 17-18, page 14 lines 31-32). I think interpretations and observations should be classified.

In section 6.2, authors are discussed the possibility of potential landslide early warning system using seismic signal. The idea is interesting, but the way of writing seems to be too optimistic. At this moment we are drawing the target around the arrow. For example, the first sentence in page 15 says the precursory tremors should be dectable, but as authors may know, there are many landslides which do not generate precursory signal. For practical purpose, the success rate also should be investigated.

[Minor comments]

Page 4, section 2.1 and 2.2 The geological setting and seismicities are difficult to configure without map. Readers may not be familiar with the area. Since it seems they are used in the later interpretation, please add figures to explain them.

Page 6 lines 1-7 Please add a map to show those events.

\section{ESurfD}

Interactive comment
Printer-friendly version

Discussion paper 
Page 6 line 18 It is not clear for me what is cigar-like shape. Could you rephrase it? (same in page 13 line 3)

ESurfD

Page 7 section 3.2 Please show the force-time history and waveform fitting (possibly in appendix)

Page 7 line 13 Remove a big space between CMG-3Ts and instruments

Interactive

comment

Page 7 line 21 Inversion would give a force (mass times acceleration). How did you compute the mass?

Page 8 line 9 There are multiple lines and these three frequencies are not easy to identify. Could you zoom-in and add lines on the figure? How about the yellow curved line between 10-15 Hz?

Page 8 lines 13-17 Please show the spectrograms of other stations (e.g. DREK, GODA, HOTT, JONS, KLUR, MOFO, STAM, VADA) in the appendix.

Page 8 lines 18-19 I am not sure why this implies the surface wave. Other phases may give a large $\mathrm{H} / \mathrm{V}$.

Page 8 lines 22-27 Please show this amplitude ratio on a map.

Page 8 lines 28-32 Please show the time window used for this localization. The word of "migration" sounds confusing for me. In general, if you say migration for tremors, the source location will migrate as a function of time. If the location is fixed when you invert the location from the cross correlation time shift, I suggest to use gridsearch.

Page 10 lines 3-10 It would be helpful if you add a geological section of the landslide to understand this description.

Page 10 lines 8-9 Why does the higher energy transmit if the stick-slip motion happens at the sliding surface? That is not intuitive.

Page 10 line 12-17 This is quite strong assumption, and I was not convinced that it was 
the only one possibility to explain this phenomenon. You wrote, "we deduce that the individual, repeating stick-slip events occurred very close together in time from the start of instability." On the other hand, "individual stick-slip events before the Askja landslide may not have been detectable kilometres away and that the events must occur already very close in time and transmit enough energy that they can be seen from a longer distance, likely as a continuous tremor signal." If you treat these tremors as summation of individual events, why the attenuation can be different? You wrote the individual events were not detectable farther away but tremor signal could transmit energy. That sounds contradictory for me.

Page 13 line 11-13 Please show the location of afterevents on a map.

Page 28 Figure 4 Why you use vertical component in Fig. 4 and EW component in Fig. $6 ?$

Page 30 Figure 5 Please show the date of the photo (a) taken.

Page 31 Fig. 6 Why are there strong signals with frequency $<1 \mathrm{~Hz}$ after the bandpass filter between $1-45 \mathrm{~Hz}$ ?

Page 32 Figure 7 Please add a scalebar for the likelihood. Please add the definition of likelihood in the main text.

Interactive comment on Earth Surf. Dynam. Discuss., https://doi.org/10.5194/esurf-2017-68, 2017. 